
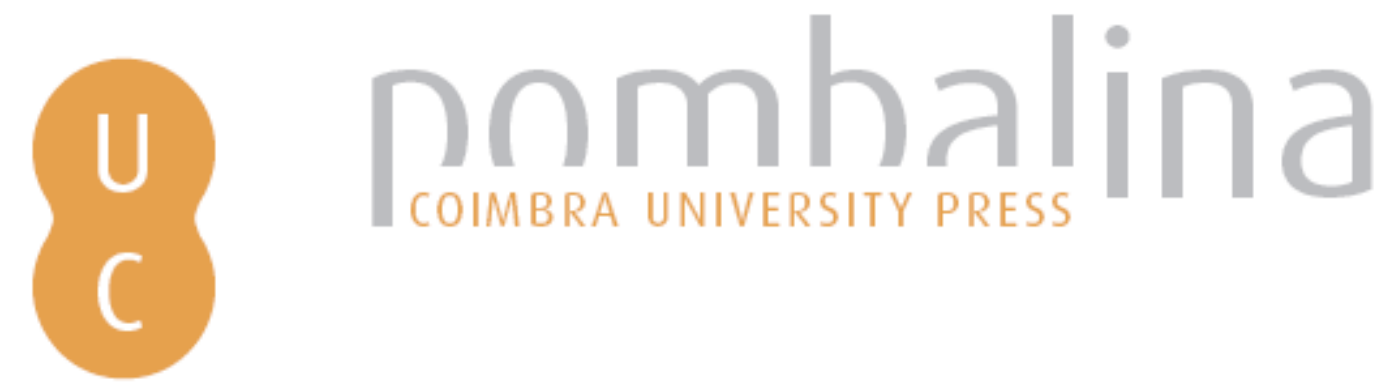

Acordes de um país tagarela: relato de discurso e construção de imagens identitárias

Autor(es): $\quad$ Figueiredo, Paula Eduarda Moreira

Publicado por: Imprensa da Universidade de Coimbra

URL

persistente: $\quad$ URI:http://hdl.handle.net/10316.2/32261

DOI: $\quad$ DOI:http://dx.doi.org/10.14195/978-989-26-0714-6_8

Accessed : $\quad$ 26-Apr-2023 14:47:42

A navegação consulta e descarregamento dos títulos inseridos nas Bibliotecas Digitais UC Digitalis, UC Pombalina e UC Impactum, pressupõem a aceitação plena e sem reservas dos Termos e Condições de Uso destas Bibliotecas Digitais, disponíveis em https://digitalis.uc.pt/pt-pt/termos.

Conforme exposto nos referidos Termos e Condições de Uso, o descarregamento de títulos de acesso restrito requer uma licença válida de autorização devendo o utilizador aceder ao(s) documento(s) a partir de um endereço de IP da instituição detentora da supramencionada licença.

Ao utilizador é apenas permitido o descarregamento para uso pessoal, pelo que o emprego do(s) título(s) descarregado(s) para outro fim, designadamente comercial, carece de autorização do respetivo autor ou editor da obra.

Na medida em que todas as obras da UC Digitalis se encontram protegidas pelo Código do Direito de Autor e Direitos Conexos e demais legislação aplicável, toda a cópia, parcial ou total, deste documento, nos casos em que é legalmente admitida, deverá conter ou fazer-se acompanhar por este aviso. 


\section{ESTUDOS DE \\ LINGUÍSTICA}

VOLUME II

CONCEIÇÃO CARAPINHA

ISABEL A. SANTOS

COORD.

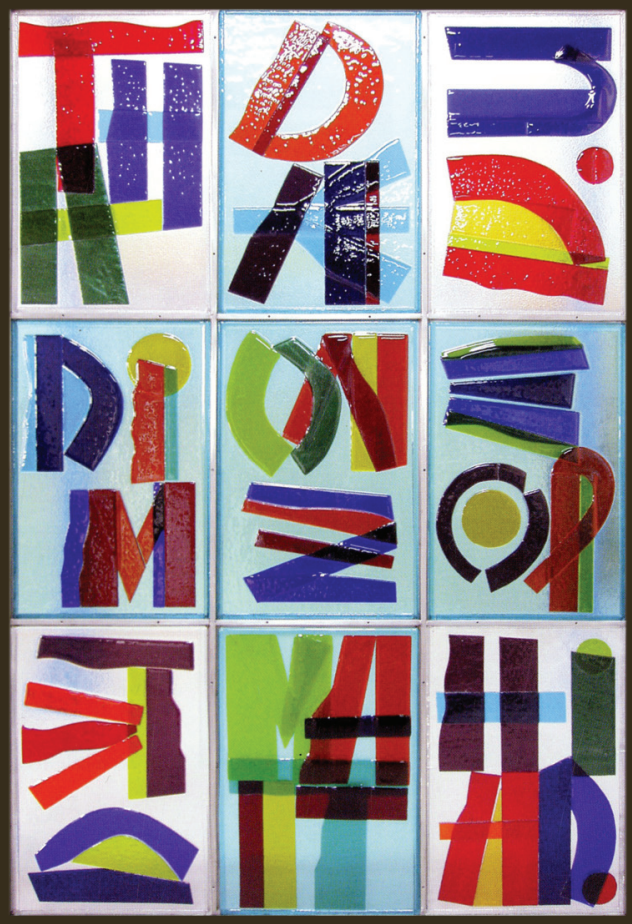


ACORDES DE UM PAís TAGARELA: RELATO DE DisCuRSO

E CONSTRUÇÃO DE IMAGENS IDENTITÁRIAS 84

Paula Eduarda Moreira Figueiredo

Faculdade de Letras da Universidade de Coimbra

paula_mfigueiredo@botmail.com

\section{Introdução}

"Assola o país uma pulsão coloquial que põe toda a gente em estado frenético de tagarelice, numa multiplicação ansiosa de duos, trios, ensembles, coros. [...] O falatório é causa de inúmeros despautérios, frouxas produtividades e más criações.

Fala-se, fala-se, fala-se, em todos os sotaques, em todos os tons e decibéis, em todos os azimutes. O país fala, fala, desunha-se a falar, e pouco do que diz tem o menor interesse. O país não tem nada a dizer, a ensinar, a comunicar. O país quer é aturdir-se. E a tagarelice é o meio de aturdimento mais à mão" (Carvalho, 2003: 11).

Estas linhas que iniciam Fantasia para dois coronéis e uma piscina ${ }^{85}$, de Mário de Carvalho (MC), e a capa semanticamente saturada da edição da Caminho - por metonímia, a piscina é Portugal ${ }^{86}$ - desafiaram-me a

84 O presente texto é produto de uma investigação levada a cabo no âmbito da dissertação de mestrado em Português como Língua Estrangeira e Língua Segunda, orientada pelas Professoras Doutoras Ana Cristina Macário Lopes e Ana Maria Machado, em 2011, na Faculdade de Letras da Universidade de Coimbra.

85 A partir de agora, o romance será referido apenas como Fantasia...

$86 \mathrm{Na}$ capa da edição consultada, sobre um fundo branco, surge uma piscina de águas azuis cujos contornos são os do retângulo lusitano (cf. Figueiredo, 2011: Anexo 2, II). 
tentar compreender se e de que modo, no romance, as vozes das personagens corroboram o axioma do narrador: a omnipresença e a vacuidade dos discursos são uma manifestação atual da idiossincrasia lusitana.

O trabalho procurou articular três vertentes - um estudo do relato de discurso (RD) numa perspetiva da Linguística da enunciação/textual, uma análise da textualização de imagens identitárias numa obra literária e uma abordagem pedagógico-didática pensada para estudantes de Português Língua Estrangeira (PLE) de nível superior de proficiência (C1) ${ }^{87}$-, cujos aspetos essenciais passo agora a expor.

\section{Formas canónicas de RD e mito como intertexto}

A reprodução, oral ou escrita, de um discurso efetivamente proferido ou pensado/antecipado, por personagens do mundo real ou do universo ficcional ${ }^{88}$ convoca mecanismos linguístico-pragmáticos simples apenas na aparência: por um lado, materializa duas situações de enunciação ${ }^{89}$, protagonizadas por dois sujeitos enunciadores - o que fala e o que cita, cada um inserido num contexto particular cujas coordenadas são essenciais para a descodificação da mensagem; por outro, a vitalidade e a criatividade da literatura, espaço de revelação "de todas as virtualidades da língua" (Aguiar e Silva, 1983, retomando um postulado coseriano), resistem ao espartilho das formas prototípicas definidas pelas gramáticas - discurso direto (DD), discurso indireto (DI) e discurso indireto livre (DIL). O RD é, por isso, um desafio para os docentes e para os alunos, confrontados com a difícil - ou mesmo, por vezes, impossível - tarefa de circunscrever fronteiras e/ou atribuir palavras/pensamentos em enunciados que transgridem as normas gramaticais e/ou tipográficas dos mecanismos de citação, ampliando dessa forma a ambiguidade enunciativa dos textos.

87 Cf. Quadro europeu comum de referência para as línguas (2002).

88 Sobre a especificidade do relato de palavras nos textos literários, veja-se, por exemplo, G. Reyes (1984).

89 Para a definição dos conceitos que aqui são aduzidos, veja-se o Dicionário Terminológico. 
Tendo em conta quer o objetivo primeiro - recensear as vozes que ecoam em Fantasia... e analisar a sua eventual relevância na configuração identitária das personagens - quer o público-alvo (discentes não-nativos de Português), a minha pesquisa focou-se em exemplos consensuais de $\mathrm{RD}$, não deixando todavia de assinalar ocorrências periféricas, como será explicitado na secção três ${ }^{90}$.

Assim, comecei por proceder a uma caracterização enunciativo-pragmática da tríade canónica do RD, considerando, em primeiro lugar, o DD: aí, concretizam-se duas situações de enunciação distintas, que produzem dois discursos sintaticamente independentes (e delimitados com dois pontos, parágrafo e travessão, entre outros marcadores formais). Nesta forma de $\mathrm{RD}$, "um locutor-relator (...) introduz o discurso objecto de citação (...), pressupondo-se a transcrição ipsis verbis que convida a uma leitura de dicto" (Figueiredo, 2011: 22-24). Ainda que o sistema de referências do enunciador citado seja mantido, o relato de palavras em DD não é neutro, uma vez que decorre de escolhas linguístico-pragmáticas do relator (Duarte, 1999: 114; 2003: 61-62). Para além disso, a reconstituição rigorosa do contexto de enunciação do discurso que é relatado - circunstância essencial quando se trata de RD - revela-se pouco provável (Figueiredo, 2011: 25). É todavia inquestionável que esta forma de reprodução de palavras busca a verosimilhança e confere grande expressividade aos enunciados (Duarte, 2003: 73-75; Reyes, 1993: 15), o que acaba por inviabilizar, em muitas situações, os exercícios de tipo transformacional habitualmente propostos pelas gramáticas e pelos livros escolares (Duarte, 2003: 51)91. O alcance pragmático da reprodução de palavras em DD - como aliás sucede com as outras formas de RD - apenas se pode aferir em cada situação específica, mas pode ir da procura de validação de um ponto de vista, por parte do locutor-citador, à reprodução do discurso de uma personagem da qual ele se demarca criticamente (Figueiredo, 2011: 26).

90 Sobre o RD, formas canónicas e propostas de modelos escalares, veja-se, e.g., L. Rosier (1999).

91 Sobre a abordagem do RD em algumas gramáticas de Português, veja-se P. Figueiredo (2011, pp. 36-44). 
No DI, ao contrário do que sucede com o DD, existe uma hierarquização sintática: o RD inicia-se com um verbo de comunicação, na oração principal, e a citação de discurso integra uma oração subordinada completiva, sendo efetivamente uma paráfrase de um discurso da responsabilidade do locutor-citador. São o seu sistema de referências e a sua subjetividade que se plasmam no enunciado, requerendo em geral uma leitura de re (Figueiredo, 2011: 27): no DI, pode manter-se a força ilocutória do enunciado primeiro, sem se respeitar o seu conteúdo proposicional (Duarte, 2003: 78-86) ${ }^{92}$. Ainda que o valor expressivo do DI seja variável, reveste-se em geral de um grau de mimetismo inferior ao alcançado pelo DD.

O DIL - cuja presença não é muito significativa em Fantasia... - foi perspetivado neste trabalho como um mecanismo discursivo que ocorre em textos literários (Duarte, 1999: 118; 2003: 125-126) e onde coexistem dois sistemas de enunciação, o do locutor-relator e o do locutor-enunciador. Por isso, é uma forma de RD eivada de subjetividade e com elevado valor mimético (Duarte, 2003: 145-147, 241).

Definidas as categorias operativas para o estudo do RD no romance de MC, e sem perder de vista que um texto literário configura universos possíveis, não mundos empíricos93, cujos "espaços em branco" (Eco, 1993) são preenchidos de acordo com a enciclopédia de cada leitor, lancei mão de um conceito da literatura comparada relevante para a análise da textualização de imagens identitárias: o de "mito (...) como un intertexto de referencia" (Cecilia, 2006: 61). Género eminentemente polifónico, o romance é um espaço textual onde ressoam sempre múltiplas vozes (Bakhtine apud Peytard, 1995). Em Fantasia..., um 'cronovelema' em permanente diálogo intertextual ${ }^{94}$, o narrador vai disseminando pistas que convocam Mofina Mendes: à semelhança da pastora vicentina, as personagens de

92 Pode registar-se também aquilo a que J. Authier-Revuz chama "ilhotas textuais" (Duarte, 2003: 93), i.e., palavras do primeiro enunciador inseridas, entre aspas, no discurso do relator.

93 Sobre literatura e representação, veja-se, e.g., J. Leerssen (1991) e J.-M. Grassin (s.d.).

94 'Cronovelema' é um neologismo de MC que, segundo o escritor, designa um subgénero narrativo onde se cruzam diversos géneros de escrita (M. J. Martins, 2003). MC considera o escritor um fiel depositário de um legado cultural e literário que deve fazer ressoar nas suas obras. Sobre esta questão, veja-se, e.g., Carvalho (1995) e Cotrim (1996). 
MC deixam-se embalar em planos irrealistas e imprevidentes, lançados por terra pela sua loquacidade irreprimível.

\section{Os dois eixos temáticos do romance: o brado e o queixume}

Fantasia... é, na verdade, uma dilatada e ruidosa analepse que, partindo do quotidiano de dois coronéis reformados, vivendo algures no Alentejo, oferece ao leitor instantâneos do quotidiano reveladores dos "tiques piores dos portugueses de hoje" (Duarte, 2004).

A proliferação de discursos torna-se evidente logo na inventariação das personagens: entram em cena mais de quatro dezenas, o que exigiu uma seleção segundo critérios de relevância na trama narrativa. De entre essas, escolhi vinte e seis, tendo procedido ao recenseamento das falas que configuram as formas de citação definidas em 2., bem como ao dos verbos introdutores de RD.

A análise dos dados relativos às 832 entradas da tabela de registo95 revelou que:

- o DD tem uma presença avassaladora no romance, contabilizando $81,3 \%$ dos registos de reprodução de discurso no discurso e dando voz a vinte e nove personagens diferentes (cf. Anexo 1);

- é também o DD que predomina quando estão em cena as principais personagens da trama narrativa - mais de dez por cento das falas de cada uma (Emanuel Elói, o elemento aglutinador no romance; Bernardes e Lencastre, os coronéis que conversam à beira da piscina; as mulheres de ambos, Maria das Dores e Maria José, respetivamente) (cf. Anexo 2);

- o DD surge preferencialmente sem verbo introdutor - 452 vezes, i.e., $66,86 \%$ das ocorrências (cf. Anexo 2);

- o narrador recorre sobretudo a verbos dicendi ${ }^{6}$ para introduzir o DD - 57 verbos diferentes, num universo de 74 (cf. Anexo 3).

95 Estes dados encontram-se no CD que acompanha a minha dissertação de mestrado (Figueiredo, 2011).

96 Optei por limitar o registo a dois tipos de verbos - dicendi e sentiendi - por duas razões: avaliar a presença e a expressividade de verbos de elocução num romance que 
Assim, é pela tirania da palavra em DD que é feita a caracterização (quer 'auto' quer 'hetero') de personagens e são revelados os ambientes sociais, profissionais e culturais em que se move - para além de Emanuel e dos dois casais - uma plêiade de outros caracteres ficcionais, peças indispensáveis do desconcertante puzzle social que o romance constrói ${ }^{97}$ : o vernáculo de Maria das Dores (pp. 29, 63 e 111); a hipocrisia, a vulgaridade e o arrivismo de Januário (pp. 52 e 58; heterocaracterização de Lencastre, p.188); a ignorância desdenhosa de Sandra, a filha de Januário (pp. 48 e 50); a negligência de Tânia, a empregada da estação de serviço, e do segurança (p. 106); a ganância de Desidério, Eleutério e Felismina (pp. 128-129); a incompetência petulante da jornalista estagiária (p. 209); as inenarráveis canções de Soraia Marina (pp. 21 e 126); a arte presunçosa de Neusa (pp. 161-162) e de Tiago (p. 164); a rebeldia adultescente de Nelson (pp. 73-75); as falas indigentes da novela televisiva (pp. 138-139).

Esta enumeração, não sendo de modo algum exaustiva, atesta a inépcia, a incivilidade, a ignorância, a petulância, a desonestidade que grassam no país, impiedosamente postas a nu pela interminável vozearia com que se atordoam os portugueses.

A presença massiva do DD comprova a coerência do narrador de Fantasia...: desencantado com o aviltamento ético, cultural e linguístico dos seus compatriotas, decide abdicar de estratégias de mediação enunciativa e coloca à boca de cena as suas personagens, a quem atribui o papel principal na encenação trágico-cómica da realidade nacional do início do século XXI. A maior parte das ocorrências em DD não tem verbo introdutor e os três verbos dicendi mais solicitados são 'dizer', 'responder' e 'perguntar'98. São opções narrativas que visam desinstalar o leitor: a neutralidade voluntária do narrador no que diz respeito ao discurso atributivo e ao modo de reproduzir as falas das suas personagens,

verbera a vozearia e tornar exequíveis propostas pedagógicas para o público-alvo definido (alunos de PLE).

97 Sobre o olhar crítico e desencantado de MC em relação ao país, que revelou em várias entrevistas a propósito deste romance, veja-se, e.g., M. João Martins (2003), L. M. Faria (2003), T. Coelho (2003) e C. Oliveira Martins (2004).

98 Cf. Anexo 3. 
revelando, em todo o seu deprimente esplendor, um país em declínio acelerado, convida ao olhar crítico do narratário.

Para além das ocorrências nas três formas de RD referidas em 1., registei dezanove exemplos de relato de palavras que classifiquei como 'modo híbrido' (2,3\% do RD) ${ }^{99}$, uma vez que apresentam algum grau de derrogação das regras canónicas, incorporando traços formais de considerável valor mimético. As subversões mais comuns dizem respeito a hibridação de características formais de DD com outras do DI ${ }^{100}$ ou de DD com DIL ${ }^{101}$ e ainda encadeamentos inesperados de diversas formas de RD (e.g., pp. 49-50). Estes casos-fronteira de RD, como já referi, testemunham a originalidade de MC e, em contexto de sala de aula, podem constituir um ponto de partida para uma reflexão fecunda sobre ortodoxia gramatical e vitalidade criativa da língua ${ }^{102}$.

O lamento inconsequente é outra das linhas temáticas que estruturam Fantasia..., logo desde o início, quando Eleutério entorna o bidão de mel que transportava na sua bicicleta. O queixume de Mofina Mendes é depois declinado em vários tons, a maior parte das vezes em $\mathrm{DD}^{103}$ : a recriação de um mito literarizado que pertence à nossa memória literária como 'intertexto de referencia' (cf. supra 2.) "sublinha a vacuidade dos discursos palavrosos, uma suposta característica identitária portuguesa: incapazes de sermos empreendedores, embalamo-nos em sonhos desmesurados que redundam sistematicamente em fracassos" (Figueiredo, 2011: 91). No romance, só Januário, o chico-esperto que foge aos impostos e se quer "meter a sério na política” (p. 188), consegue prosperar.

99 Cf. Anexo 1.

100 "Que não, fazia-se tarde, disse Emanuel, sem saber como explicar que não era professor - tomara ele aprender - e que o título de mestre no xadrez não tinha que ver com graus académicos" (p. 56).

101 "Injustiça!, concluía Sandra, as canções, a música deviam ser de toda a gente, como as esferográficas, os clips, os isqueiros. O primeiro que chegar pega, e leva. Agora esta coisa de estar a proteger o egoísmo duns tipos que lá por serem autores só querem é lucro, ganhuça, ganhuça, francamente, não estava certo" (p. 50).

102 Nomeadamente, a partir de um excerto em que ecoa a voz de Tiago e que é refratário a qualquer classificação dentro do cânone do RD (cf. pp. 163-164 do romance).

103 Cf. Anexo 4. 
Apenas um leitor enciclopedicamente competente conseguirá fruir deste diálogo intertextual que introduz no texto uma espessura semântica tão cara ao escritor. Numa aula de PLE, este vetor semântico permitiria não apenas estabelecer um elo entre Gil Vicente e a literatura contemporânea como também reconhecer um tópico do universo literário de $\mathrm{MC}^{104}$.

\section{Abordagem pedagógico-didática ${ }^{105}$}

Fantasia... não é de modo algum um texto fácil, mas o desafio linguístico e literário que representa, bem como o divertimento que inegavelmente proporciona justificam a escolha do romance para estudo em contexto de aula de PLE com alunos universitários de nível C1.

A leitura integral da obra e a análise/discussão em grande grupo fomentariam as competências comunicativas dos alunos, nas suas várias vertentes (e.g., linguístico-pragmática, estético-literária, sociocultural) ${ }^{106}$, encorajariam a reflexão individual, o confronto de pontos de vista sobre Portugal e sobre os diferentes países de origem dos discentes, permitindo ainda aprofundar a reflexão metalinguística sobre os mecanismos de RD.

\subsection{Reflexão sobre a importância das coordenadas contextuais nos mecanismos de reprodução de discurso no discurso}

Tarefa: Reescrever em DI os excertos do DD de Emanuel e registar as conclusões, comparando-as com as regras das gramáticas normativas.

${ }^{104}$ Mofina Mendes é recuperada em Quando o diabo reza: Cíntia dança arrebatadamente ao imaginar um futuro luminoso, colocando em perigo o garrafão de azeite trazido de Celorico. Quando o marido chega a casa, "ia em todo o andar um cheiro a azeitum" (Carvalho, 2011: 102).

105 Os exercícios apresentados em 3.1. e 3.2. são excertos da proposta de didatização elaborada no âmbito da minha dissertação de mestrado (Figueiredo, 2011: 104-110, Anexos 12 a 14 , XXVI-XXXVII).

106 Foi Hymes quem cunhou o conceito de 'competência comunicativa', definindo-a como "o conhecimento (prático e não necessariamente explicitado) das regras psicológicas, culturais e sociais que comandam a utilização da fala num enquadramento social" (apud Galisson \& Coste, 1983: 134). 


\begin{tabular}{|c|c|c|c|}
\hline $\begin{array}{l}\text { Discurso } \\
\text { direto }\end{array}$ & $\begin{array}{l}\text { Coordenadas contextuais: quem fala, a } \\
\text { quem fala, de quem fala }\end{array}$ & $\begin{array}{l}\text { Discurso } \\
\text { indireto }\end{array}$ & Conclusões \\
\hline \multirow{3}{*}{$\begin{array}{l}\text { Emanuel dirige-se a } \\
\text { Eleutério: } \\
\text { " - Pois eu [...] fico } \\
\text { [...] em Reguengos, } \\
\text { falo com a sua rapari- } \\
\text { ga [...]." (p. 35) }\end{array}$} & $\begin{array}{l}\text { O dono do restaurante de Reguengos } \\
\text { conta à mulher a conversa que ouviu. }\end{array}$ & & \\
\hline & $\begin{array}{l}\text { Emanuel reproduz a Eleutério as pala- } \\
\text { vras que ele próprio proferiu. }\end{array}$ & & \\
\hline & $\begin{array}{l}\text { Eleutério reproduz perante Emanuel as } \\
\text { palavras que este lhe dirigiu. }\end{array}$ & & \\
\hline
\end{tabular}

\subsection{Enriquecimento lexical, a partir de verbos introdutores de RD}

Tarefa: Propor um verbo que possa introduzir o DD de cada personagem.

\begin{tabular}{|l|l|}
\hline Excerto do romance & Reescrita do excerto \\
\hline [DD de Emanuel, p. 35] & \\
"O automóvel patinou na massa de areia, deu-se a uns ziguezagues & \\
perigosos, mas Emanuel firmou-se bem ao volante. & \\
- Quer vossemecê que eu fale com ela?” & \\
\hline [DD do organizador da festa de Grudemil, p. 47] & \\
"O homem segurou familiarmente o braço de Emanuel, e para a & \\
rapariga: & \\
- Sandra, minha amiga, bem vês, vais fazer um favor à organização: & \\
conduzes aqui o professor à tenda dos ranchos. Já vamos atrasados, & \\
bem vês. É para começar às cinco, não é, professor?” & \\
\hline
\end{tabular}

\subsection{Análise de excertos do romance}

Leitura e análise de dois excertos: aquele em que o narrador procede à caracterização da voz de Januário (pp. 52-60) que, "tranquila, levemente enfadada" (p. 52) no início, se transforma em "vozeirão" (p. 60), prestando particular atenção ao DD e às suas funcionalidades no processo de construção da personagem; aquele em que o narrador descreve a festa em Grudemil (pp. 44-45) e o seu papel na textualização de imagens de Portugal. 


\subsection{Outras leituras}

Pesquisa sobre as capas das edições estrangeiras do romance ${ }^{107}$, para confronto e discussão de pontos de vista, e leitura/comentário da reportagem Revolução na festa da aldeia, de Ricardo Rodrigues (2012), fazendo o contraponto com o excerto de Fantasia... analisado anteriormente.

\section{Conclusões}

A abordagem enunciativo-pragmática do RD, em contexto de ensino-aprendizagem, permite uma reflexão metalinguística profícua, quer sobre as formas canónicas quer sobre manifestações periféricas do relato de palavras, sensibilizando os alunos para os recursos da língua que são convocados e para os seus efeitos expressivos e pragmáticos.

Enquanto espaço potenciador da criatividade da língua, a obra literária, intrinsecamente polifónica, alimenta um diálogo intertextual enriquecedor e abre aos alunos múltiplas e fecundas vias de descoberta de si próprios, do(s) Outro(s) e do mundo.

Em Fantasia..., a análise da presença, do peso e das características das vozes das personagens mais significativas para a trama narrativa comprovou existir uma homologia entre forma e conteúdo: a proliferação de falas que inundam, em DD, um romance de estrutura caleidoscópica atesta a alienação em que se entretém um país chocalheiro, inepto e sem consciência de que o é. O retrato marcadamente disfórico traçado pelo narrador deixa antever a resposta à questão por ele formulada, ao cair do pano: "Há emenda para este país?" (p. 227).

107 Fantasia... foi até à data editado em França, na Croácia e em Espanha, de acordo com informação disponível na página pessoal do escritor. 


\section{Referências bibliográficas}

Carvalho, Mário de (1995): O romance está em aberto. In: Jornal de Letras, Artes e Ideias $647,16$.

Carvalho, Mário de (2003): Fantasia para dois coronéis e uma piscina. Lisboa: Caminho.

Carvalho, Mário de (2011): Quando o Diabo reza. Lisboa: Tinta-da-China.

Carvalho, Mário de: Página pessoal [On-line], disponível em: <http://www.mariodecarvalho. com/>. [Consultado em: $08 \mathrm{dez} .2012]$.

Cecilia, Juan H. (2006): El mito como intertexto: la reescritura de los mitos en las obras literarias. In: Çédille. Revista de estudios franceses, $\mathrm{n}^{\circ} 2$ (Abril 2006), 58-76. [On-line], disponível em: <http://webpages.ull.es/users/cedille/dos/cedille-dos.pdfs. [Consultado em: 02 out. 2007].

Coelho, Tereza (2003): Mário de Carvalho. O livro do país patusco. In: PÚBLICO - Mil Folhas, 10/06/2003, 4-7.

Conselho da Europa (2002): Quadro europeu comum de referência para as línguas. Aprendizagem, ensino, avaliação. Trad. M. Joana P. do Rosário e Nuno V. Soares. Ministério da Educação/ GAERI (coord. da ed.). Porto: Asa Editores.

Cotrim, J. P. (1996): Mário de Carvalho, "Alguma coisa me perturba". In: Ler. Livros \& Leitores 34, 38-49.

Dicionário Terminológico, disponível em: <http://dt.dgidc.min-edu.pt/>. [Consultado em: dez. 2012).

Duarte, Isabel M. (1999): As vantagens de uma gramática do texto para o estudo do relato de discurso. In: C. Mello (org.), I Jornadas Científico-Pedagógicas de Português. Instituto de Língua e Literatura Portuguesas da Faculdade de Letras da Universidade de Coimbra. Coimbra: Livraria Almedina, 113-120.

Duarte, Isabel M. (2003): O relato de discurso na ficção narrativa. Contributos para a análise da construção polifónica de Os Maias de Eça de Queirós. Lisboa: Fundação Calouste Gulbenkian/Fundação para a Ciência e a Tecnologia. [1999, Tese de doutoramento, Faculdade de Letras da Universidade do Porto].

Duarte, Isabel M. (2004): A primeira vez que eu li Fantasia para dois coronéis e uma piscina, de Mário de Carvalho. In: Primeir@Prova - Revista Electrónica de Línguas e Literaturas Modernas - Departamento de Estudos Portugueses e Estudos Românicos da FLUP, $\mathrm{n}^{\circ} 0$ [On-line], disponível em:

<http://repositorioaberto.up.pt/bitstream/10216/23649/2/isabelduarteprimeiraprova000096437.pdf>. [Consultado em: 09 dez. 2012).

Eco, Umberto (1993): Leitura do texto literário - lector in fabula. Lisboa: Editorial Presença, 53-70.

Faria, L. M. (2003): Mário de Carvalho. Muitas palavras, pouca conversa. In: EXPRESSO 1621 - Actual, 46-47.

Figueiredo, Paula (2011): Relato de discurso e Fantasias do Portugal contemporâneo na aula de Português Língua Estrangeira. [Dissertação de mestrado, Faculdade de Letras da Universidade de Coimbra].

Galisson, R. / Coste D. (1983). Dicionário de Didáctica das Linguas. Coimbra: Almedina, 134-135, 442-445.

Grassin, J.-M. (s/d): Image. In: Escarpit, Robert (org.), Dictionnaire International des Termes Littéraires. [On-line], disponível em: <http://www.ditl.info/arttest/art2241.php>. [Consultado em: 13 jul. 2008). 
Leerssen, Joep (1991): Mimesis and Stereotype. In: Leerssen, J. et al. (edd.), Yearbook of European Studies 4, Amsterdam: Rodopi, 165-175.

Martins, C. Oliveira (2004): Mário de Carvalbo. Pátria lusitana. O retrato, a ironia e o desencanto. In: Os Meus Livros, 19, 38-43.

Martins, M. João (2003): Mário de Carvalho: crónica do aturdimento. In: Jornal de Letras, Artes e Ideias, 864, 10-12.

Peytard, Jean (1995): Mikhail Bakhtine. Dialogisme et analyse du discours. Paris: BertrandLacoste.

Reyes, Graciela (1984): Polifonía textual. La citación en el relato literario. Madrid: Editorial Gredos.

Reyes, Graciela (1993): Los procedimientos de cita: estilo directo y estilo indirecto. Madrid: Arco/ Libros.

Rodrigues, Ricardo J. (2012): Revolução na festa da aldeia. In: Notícias Magazine 1056, 46-57.

Rosier, Laurence (1999): Le discours rapporté. Histoire, théories, pratiques. Bruxelles: Duculot.

Silva, V. M. Aguiar e (1983): Teoria da Literatura. Coimbra: Livraria Almedina, 43-44, 90$107,112-113,144-150,171-173,258-265,300-329$.

Vicente, Gil (1984): Compilaçam de todalas obras de Gil Vicente. Vol. I, Lisboa: Imprensa Nacional/ Casa da Moeda, 102-124.

Anexos $^{108}$

\section{Anexo 1}

\begin{tabular}{|l|c|c|c|}
\hline Tipo de RD & $\begin{array}{c}\mathbf{N}^{\mathbf{0}} \text { de ocorrências } \\
\text { (em 832 registos) }\end{array}$ & $\begin{array}{c}\text { \% na totalidade } \\
\text { do romance }\end{array}$ & $\begin{array}{c}\mathbf{N}^{\mathbf{0}} \text { de vozes diferentes } \\
\text { no romance }\end{array}$ \\
\hline DD & 676 & $81,3 \%$ & 29 \\
\hline DIL & 54 & $6,5 \%$ & 17 \\
\hline $\begin{array}{l}\text { Reprodução de palavras } \\
\text { no discurso do narrador }\end{array}$ & 40 & $4,8 \%$ & 13 \\
\hline DI & 28 & $3,4 \%$ & 13 \\
\hline Modo híbrido & 19 & $2,3 \%$ & 11 \\
\hline DDL & 15 & $1,8 \%$ & 8 \\
\hline
\end{tabular}

108 Os anexos foram elaborados com base nos documentos que integram a secção "Anexos» da minha dissertação de mestrado (Figueiredo, 2011). 
Anexo 2

\begin{tabular}{|c|c|c|c|c|c|}
\hline Voz citada & $\begin{array}{l}\% \text { na totalidade } \\
\text { do romance }\end{array}$ & $\begin{array}{l}\text { Falas } \\
\text { em DD }\end{array}$ & $\begin{array}{l}\text { \% de falas em DD } \\
\text { (na totalidade do } \\
\text { discurso da }\end{array}$ & \multicolumn{2}{|c|}{$\begin{array}{l}\text { Verbos introdutores } \\
\text { de discurso direto }\end{array}$} \\
\hline Emanuel Elói & $14,7 \%$ & 95 & $11,5 \%$ & $\begin{array}{l}\text { Total de ocor- } \\
\text { rências em DD }\end{array}$ & 676 \\
\hline $\begin{array}{l}\text { Maciel } \\
\text { Bernardes }\end{array}$ & $14,2 \%$ & 98 & $11,8 \%$ & $\begin{array}{l}\text { Sem verbo } \\
\text { introdutor }\end{array}$ & $\begin{array}{c}452 \\
(66,86 \%)\end{array}$ \\
\hline $\begin{array}{l}\text { Maria das } \\
\text { Dores }\end{array}$ & $11,8 \%$ & 89 & $10,7 \%$ & $\begin{array}{l}\text { Com verbo } \\
\text { introdutor }\end{array}$ & $\begin{array}{c}224 \\
(33,13 \%)\end{array}$ \\
\hline $\begin{array}{l}\text { Amílcar } \\
\text { Lencastre }\end{array}$ & $11,5 \%$ & 88 & $10,6 \%$ & $\begin{array}{l}\text { Total de ver- } \\
\text { bos diferentes } \\
\text { utilizados }\end{array}$ & 74 \\
\hline Narrador & $8,7 \%$ & 60 & $7,2 \%$ & & \\
\hline Outras vozes & $7,3 \%$ & 42 & $5 \%$ & & \\
\hline
\end{tabular}

\section{Anexo 3}

\begin{tabular}{|l|l|}
\hline \multicolumn{2}{|c|}{ Verbos introdutores de discurso direto 109} \\
\hline \multirow{2}{*}{$\begin{array}{l}\text { Verbos } \\
\text { dicendi: } \mathbf{5 7}\end{array}$} & $\begin{array}{l}\text { Aconselhar (2), acrescentar, advertir, alegar, anunciar (2), apelar, atalhar, bradar } \\
\text { (4), chamar, concluir (2), confessar (3), confessar-se, contar (3), discutir, dizer } \\
\text { (46), ecoar, elucidar, esclarecer, esganiçar-se, exclamar, explicar (3), explicitar } \\
\text { (2), filosofar, flautear, gabar-se, garantir, gritar (5), indagar, informar, insistir (4), } \\
\text { interrogar-se, interromper (2), ironizar, murmurar (2), observar (5), obtemperar, } \\
\text { ordenar, perguntar (16), perguntar-se, proclamar, propor, protestar (2), queixar-se } \\
\text { (2), ralhar, recitar, relatar (2), rematar (2), resmonear, resmungar, responder (17), } \\
\text { resumir, segredar (5), sentenciar, sugerir, sussurrar (4), trautear, vozeirar }\end{array}$ \\
\hline $\begin{array}{l}\text { Verbos } \\
\text { sentiendi: } \\
\mathbf{1 7}\end{array}$ & $\begin{array}{l}\text { Admirar, admirar-se (2), ameaçar, aprovar, assustar-se, brincar, comover-se, com- } \\
\text { preender (2), considerar (2), desconfiar, entusiasmar-se, exultar, pensar (13), pre- } \\
\text { ocupar-se, reflectir, sobressaltar-se, surpreender-se (2) }\end{array}$ \\
\hline
\end{tabular}

109 O número de ocorrências de cada verbo está registado entre parênteses. Por defeito, não havendo nenhuma indicação, trata-se de uma única ocorrência. 
Anexo 4

\begin{tabular}{|l|c|}
\hline \multicolumn{1}{|c|}{ Variações sobre Mofina Mendes } & Página \\
\hline $\begin{array}{l}\text { [Eleutério - DD] "Sendo-me a dita cruel, senhores, não me deis guerra: que todo } \\
\text { o humano aranzel, como o meu bidão de mel, há-de dar consigo em terra". }\end{array}$ & 13 \\
\hline $\begin{array}{l}\text { [Emanuel - DD] "Pensou o rapaz: Por mais que a dita o descreia, senhora, não } \\
\text { lhe deis mágoa. Que a humanal verborreia, como o camião de areia, há-de dar } \\
\text { consigo n'água. Antes, pressentindo o desfecho, Emanuel tinha suplicado a Irina } \\
\text { que suspendesse a narração:- Não, por favor, pare, não me diga...”. }\end{array}$ & 37 \\
\hline $\begin{array}{l}\text { [Ilhota textual no discurso do narrador] "Nesta matéria, reflectiu soturnamente o } \\
\text { taberneiro que seria boa ocasião para uns versos em que mossa rimasse com dar } \\
\text { consigo na fossa". }\end{array}$ & 43 \\
\hline $\begin{array}{l}\text { [Pensamentos de Emanuel] "Suspirando e pensando, se me ferir a ventura, mes- } \\
\text { tres não me deis mais guerra, que toda a humanal candura, como esta minha } \\
\text { abertura, há-de dar consigo em terra". }\end{array}$ & 100 \\
\hline $\begin{array}{l}\text { [Maria José] "Se eu fosse dar-lhe ouvidos, onde é que esses projectos me levari- } \\
\text { am? Davam comigo em terra, seguramente". }\end{array}$ & 102 \\
\hline $\begin{array}{l}\text { [Comandante da escuna] "Mas antes disso ainda conseguiu ganir: Por mais que } \\
\text { me enjeite a sorte, é melhor não disparar, um marujo bruto e forte, com o meu } \\
\text { altivo porte, há-de dar o corpo ao mar". }\end{array}$ & 119 \\
\hline [Felismina] "Agora aqui é só desgraças". & 130 \\
\hline $\begin{array}{l}\text { [Lavrador] "Agora soluçava, em sobressaltos quase gritados (...). E apesar de } \\
\text { toda aquela iniludível dor (...)". }\end{array}$ & $152-153$ \\
\hline
\end{tabular}

